\title{
Crystal structure of human E-cadherin-EC1EC2 in complex with a peptidomimetic competitive inhibitor of cadherin homophilic inter- action.
}

\author{
Valentina Nardone, ${ }^{\mathrm{a}, \mathrm{b} \pm}$ Anna Paola Lucarelli, ${ }^{\mathrm{a} \pm}$ Andrea Dalle Vedove, ${ }^{\mathrm{a}, \mathrm{b} \pm}$ Roberto Fanelli, ${ }^{\mathrm{c}}$ Anto- \\ nella Tomassetti, ${ }^{\mathrm{d}}$ Laura Belvisi, ${ }^{\mathrm{e}}$ Monica Civera, ${ }^{\mathrm{e}}$ Emilio Parisini ${ }^{\text {a, }}$, \\ ${ }^{a}$ Center for Nano Science and Technology @PoliMi, Istituto Italiano di Tecnologia, Via G. Pascoli 7o/3, 20133 Mila- \\ no, Italy \\ ${ }^{\mathrm{b}}$ Dipartimento di Chimica, Materiali and Ingegneria Chimica "Giulio Natta", Politecnico di Milano, Via L. Mancinelli \\ 7, 20131 Milano, Italy \\ ${ }^{\mathrm{c}}$ Dipartimento di Scienza e Alta Tecnologia, Università degli Studi dell'Insubria, Via Valleggio 11, 2210o Como, Italy \\ ${ }^{\mathrm{d}}$ Dipartimento di Oncologia Sperimentale e Medicina Molecolare, Fondazione IRCCS Istituto Nazionale dei Tumori, \\ Via G. Amadeo 42, 20133 Milano, Italy \\ ${ }^{\mathrm{e}}$ Dipartimento di Chimica, Università degli Studi di Milano, Via C. Golgi 19, 20133 Milano, Italy
}

KEYWORDS: cell adhesion, inhibitor, modulator, peptidomimetic, drug delivery, crystal structure

\begin{abstract}
Cadherins are transmembrane cell adhesion proteins whose aberrant expression often correlates with cancer development and proliferation. We report the crystal structure of an E-cadherin extracellular fragment in complex with a peptidomimetic compound that was previously shown to partially inhibit cadherin homophilic adhesion. The structure reveals an unexpected binding mode and allows the identification of a druggable cadherin interface, thus paving the way to a future structure-guided design of cell adhesion inhibitors against cadherin-expressing solid tumors.
\end{abstract}

\section{INTRODUCTION}

Cadherins are transmembrane calcium-dependent cell adhesion molecules that are mostly localized at the intercellular junctions and are known to play a crucial role in tissue morphogenesis and architectural integrity., Many functional studies have shown that aberrant expression of epithelial E-cadherin $\left(\mathrm{CDH}_{1}\right)$ and neuronal $\mathrm{N}$-cadherin $\left(\mathrm{CDH}_{2}\right)$ often correlates with tumor progression., In fact, the switch in expression from E-to N-cadherin is a key event in the cellular epithelial-to-mesenchymal transition (EMT) that takes place as cancer progresses. Despite its tumor repressor role in the majority of carcinomas, in epithelial ovarian cancer (EOC) cells E-cadherin shows a high level of expression during tumor progression and facilitates EOC cell proliferation. ${ }^{5}$ Interestingly, most cadherin family members are now being considered important pharmaceutical targets. For instance, a role for Pcadherin $\left(\mathrm{CDH}_{3}\right)$ in different types of cancer, such as in malignant melanoma, breast, gastric, lung, colorectal and pancreatic cancer has also been clearly identified. ${ }^{6,7}$ Therefore, efforts to develop therapeutic agents against Pcadherin have recently intensified. ${ }^{8}$ Likewise, increased expression of cadherin-11 (CDHı) on poorly differentiated highly invasive breast cancer cell lines is also associated with EMT and tumor progression. ${ }^{9,10}$ Furthermore, cadherin-11 is a validated therapeutic target in rheumatoid arthritis (RA). ${ }^{11}$ Hence, efforts to develop effective therapeutic agents against cadherin-11 are also under way. ${ }^{12}$

Cadherins mediate cell-cell adhesion by means of a concerted mechanism whereby proteins protruding from opposing cells interact with each other at the cellular adherens junctions. All classical cadherin family members share a high degree of homology and structural similarity. Classical cadherins comprise an elongated extracellular portion formed by five immunoglobulin-like extracellular cadherin domains (ECs) arranged in tandem, and an intracellular portion whose dynamic association with cytoplasmic molecules called catenins provides a physical link between the membrane-bound cadherins and the actin cytoskeleton. Structural and mutational studies on several type-I classical cadherin family members such as E-, N-, $\mathrm{P}$ - and C-cadherin have clearly shown that dimerization of two cadherin molecules protruding from the surface of two neighboring cells at the adherens junction occurs through a highly dynamic strand-exchange mechanism involving the opening of a 6-residue long N-terminal portion of the protein, usually referred to as the adhesion arm, and the mutual insertion of the side chain of the conserved Trp2 residue into the highly conserved acceptor pocket in the $\mathrm{EC}_{1}$ of the partner molecule (Fig. 1, A and C).$^{13^{-19}}$ Likewise, in type-II classical cadherins, such as cadherin-11, cadherin-8 and MN-cadherin, a similar 
mechanism involves the simultaneous mutual insertion of the side chain of the conserved Trp2 and Trp4 residues into the binding pockets in the partner molecule's $\mathrm{EC}_{1}$, providing a tighter link and a larger interface between the two interacting monomers relative to type-I cadherins. ${ }^{20,21}$

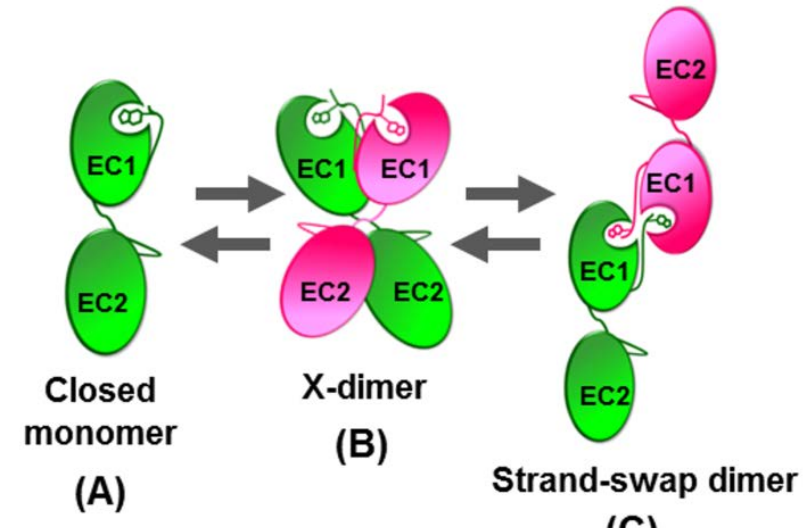

(C)

Figure 1 Schematic of the dynamic dimerization mechanism that leads from monomeric cadherin (A) to strand swap dimer formation (C) and back. The mechanism is characterized by the opening of the adhesion arm of two interacting cadherins and the mutual insertion of the Trp2 side chain in the binding pocket of the partner molecule. This process occurs via the formation of a weakly adhesive intermediate configuration which is usually referred to X-dimer (B) and has been shown to facilitate arm opening by lowering the energy barrier associated with strand swap dimer formation.

Interestingly, the highly dynamic cadherin dimerization pathway that leads from monomeric cadherin to stranddimer formation and back involves a number of crucial intermediate steps that are critical not only for cell adhesion but also for conferring specificity to the cellular recognition process during tissue morphogenesis. Along the complex trajectory that leads from monomers to strand-swap dimers and back, cadherins have been shown to go through an intermediate dimeric state characterized by stabilizing contacts between two cadherin molecules at the level of their $\mathrm{Ca}^{2+}$-binding site between the $\mathrm{EC}_{1}$ and EC2 domains (Fig. 1, B). This arrangement, usually referred to as the X-dimer $r^{14,15,22-24}$, provides a weak adhesive force between cadherin molecules ${ }^{25}$ and facilitates subsequent strand-swap dimer formation by lowering the energy barrier associated with the strand swapping process, suggesting that X-dimer formation is one of the major structural "checkpoints" along the cadherin dimerization pathway that leads from monomeric cadherin to strand dimer formation. ${ }^{26} \mathrm{~A} \mathrm{~K}_{\mathrm{d}}$ value in the sub-millimolar range has been estimated for the homophilic adhesion of classical type I cadherins. ${ }^{23,27}$

Owing to this intrinsic dynamic behavior, the rational design of small ligands targeting cadherin homophilic interactions has proved difficult and, to date, no crystal structure exists of a complex between a cadherin molecule and an inhibitor. Early structural studies suggested an important contribution of the His79-Ala8o-Val81 (HAV) and the Ile53-Asn54-Pro55 (INP) sequences to the cadherin homophilic binding mechanism. ${ }^{13}$ As a result, libraries of cyclic peptides based on HAV or INP sequences and of non-peptide HAV mimics were developed and tested for their ability to inhibit the cadherin dimerization process. ${ }^{28-30}$ Based on these studies, the antagonist peptide N-Ac-CHAVC-NH2 (ADH-1 or Exherin ${ }^{\mathrm{TM}}$ ) is now in phase I clinical trials in patients with $\mathrm{N}$-cadherinexpressing solid tumors. ${ }^{31-33}$ However, its binding interface and mechanism of inhibition are still totally unknown.

Protein-protein interfaces, especially homo-oligomers, are usually flat and featureless. Therefore, they are generally either completely undruggable or difficult to target with efficient antagonists. ${ }^{34,35}$ This is especially true for highly dynamic systems that undergo major conformational changes as part of their substrate recognition mechanism. The cadherin homo-dimerization and activation mechanism falls within this realm and it is not surprising that, to date, almost no modulators or inhibitors of cadherin-mediated cell-cell adhesion have been developed. Moreover, no actual structural evidence regarding the mechanism through which successful modulation of cadherin homo-association may actually occur has yet been provided, thus making the development of effective antagonists particularly difficult.

\section{RESULTS AND DISCUSSION}

In one of the first attempts to target the cadherin strand dimer interface identified earlier by X-ray diffraction analysis, we have previously designed and synthesized a library of small peptidomimetic molecules featuring a conformationally constrained tetra-peptide scaffold from the native N-terminal DWVI sequence where a

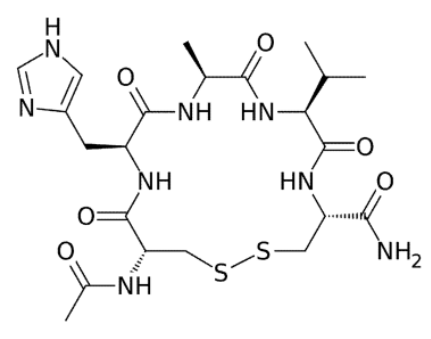

ADH-1

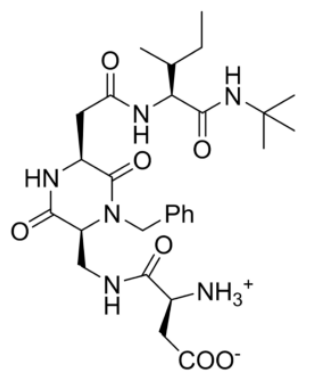

FR159
Figure 2 Structure of ADH-1 and FR159. Given their structural differences, it is unlikely that they share identical binding sites.

phenyl ring was introduced to mimic the indole moiety of the crucial Trp2 residue. ${ }^{36}$ By a combination of biochemical and functional assays, we have also shown that, even at $\mu \mathrm{M}$ concentrations, some of these peptidomimetic compounds have a significantly higher ability to inhibit $\mathrm{N}$ - and, to a slightly lower extent, E-cadherin homophilic adhesion compared to ADH-1. ${ }^{36}$ For instance, FR159 (Fig. 2) is more effective than ADH-1 in inhibiting both $\mathrm{N}$ - and E-cadherin homophilic binding. In ELISA tests using $\mathrm{N}$ cadherin-expressing epithelial ovarian cancer (EOC) cells $\mathrm{SKOV}_{3}$ and N-cadherin-Fc chimeric protein, FR159 inhibited $\mathrm{N}$-cadherin homophilic binding by $84 \%$ and by 

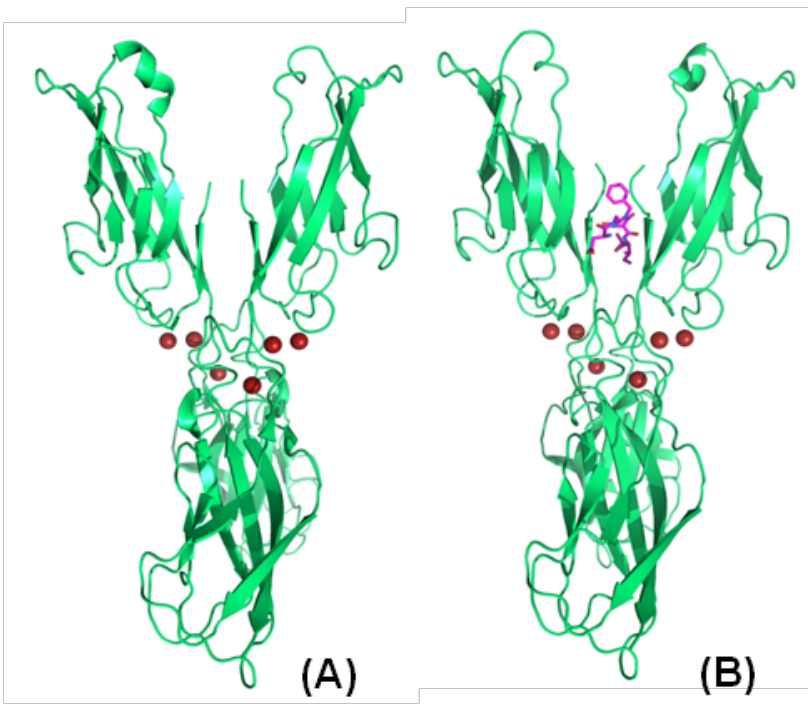

Figure 3 Crystal structure of the human E-cadherin-(Val3)EC1EC2 fragment (residues 3-213) in its un-ligated form (PDB id: 4ZT1) (A) and in complex with FR159 (PDB id: 4ZTE) (B).

$65 \%$ at $2 \mathrm{mM}$ and at $1 \mathrm{mM}$ concentration, respectively, while ADH-1 showed $50 \%$ inhibition at $2 \mathrm{mM}$ concentration and virtually no inhibition at $1 \mathrm{mM}$. Cell-free Surface Plasmon Resonance (SPR) experiments using the $\mathrm{N}$ cadherin-Fc recombinant protein showed that at $10 \mu \mathrm{M}$ concentration FR 159 provides $55 \%$ inhibition of $\mathrm{N}$ cadherin homophilic binding, compared to $28 \%$ for ADH1. In ELISA tests conducted using the E-cadherinexpressing EOC cell line OAW42 FR159 provided about $50 \%$ inhibition at $2 \mathrm{mM}$ concentration, while $\mathrm{ADH}-1$ showed only $30 \%$ inhibition. Here, we show the crystal structure of the complex between the E-cadherin-EC1EC2 fragment and FR159, one of the best inhibitory peptides that have been reported to date. The structure allows the identification of a novel druggable interface and provides, for the first time, a structural framework to guide the design of modulators of cadherin-mediated cell adhesion.

Previous attempts to co-crystallize the wt-human Ecadherin-EC1EC2 fragment (residues 1-213) with several small molecule ligands did not yield results, mostly owing to the highly dynamic behavior of the protein. We then removed the first two amino acids (Asp-Trp) at the $\mathrm{N}$ terminus of the $\mathrm{EC}_{1} \mathrm{EC}_{2}$ construct and produced the $\mathrm{E}$ cadherin-(Val3)-EC1EC2 fragment (residues 3-213), where the Trpz-binding pocket is intrinsically un-occupied and, in principle, more easily accessible to the ligand. Crystallization of this shorter protein fragment with the same panel of peptidomimetic compounds yielded co-crystals only with FR159, likely owing to the intrinsic conformation of the ligand.

Fig.3 shows a side by side comparison of the Ecadherin-(Val3)-EC1EC2 structure in the absence (A) and in the presence (B) of FR159. As expected, due to the removal of the key Trp2 residue that is used by the protein in the final stage of its complex dimerization mechanism, the protein is unable to promote strand swap dimer formation and it is found in the X-dimer configuration, an arrangement that has been previously shown to represent a crucial intermediate along the full cadherin dimerization trajectory. In essence, by removing the Asp1-Trp2 Nterminal fragment, we reduced the degree of conformational freedom of the cadherin association complex by preventing the X-dimer to progress towards strand swap dimer formation. A comparison of the two structures shows that the protein dimers superimpose with an r.m.s.d. of $0.4 \AA$ for main chain atoms.

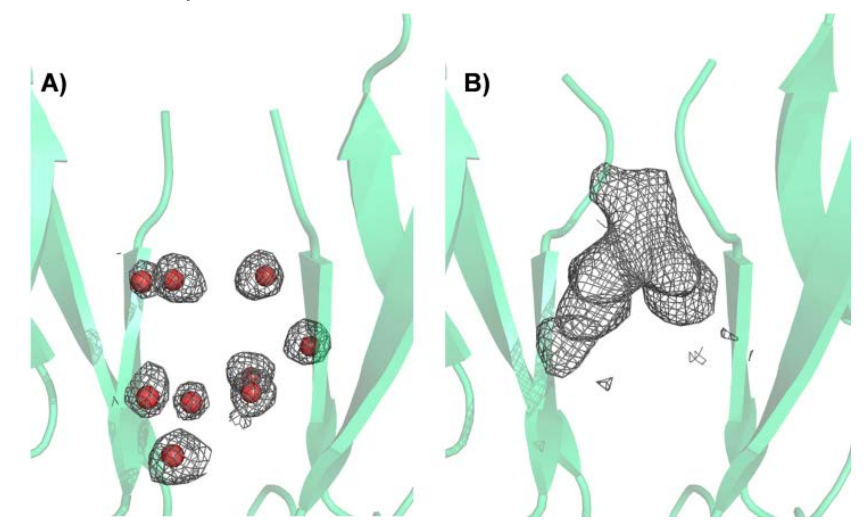

Figure 4 Side by side comparison of the electron density map in the binding region between the un-ligated (A) and the ligated (B) structure (PDB id: 4ZT1 and 4ZTE, respectively).

The preliminary computational studies that we carried out using both E- and N-cadherin suggested that the ligand may bind the protein by inserting the scaffold benzyl ring into the hydrophobic pocket of Trp2 and receive further stabilization by a number of additional contacts with the protein (see the Supplementary Information for the best computational pose of FR159 into the E- and the Ncadherin binding site). ${ }^{36}$ However, in the crystal the ligand does not bind in the expected Trp2 pocket and the Xray structure described here combined with previous cell adhesion inhibition data reveals a new target site for the design of cadherin inhibitors. In fact, the ligand binds across the two interacting cadherin molecules at the level of the di-proline motif of their adhesion arm. In the unligated structure, several water molecules occupy the space that is taken by the peptidomimetic molecule in the ligated structure (Fig. 4). The phenyl ring of the peptidomimetic ligand fits into an hydrophobic cavity formed by the side chains of residues Ile4, Pro5, Ile7 and Val22 from both cadherin molecules. The Val3 residues from the two interacting molecules are not visible in the map but it is conceivable that they may transiently cap the hydrophobic cavity, thus providing further stabilization energy to the complex. The hydrophobic cavity is symmetrical as it is formed by exactly the same group of residues from the two interacting proteins. The electron density map of the ligand in the crystal is shown in Fig. 5, A while a schematic representation of the interactions between the phenyl ring of the ligand and the surrounding molecules is shown in Fig. 5, B. Interestingly, all the residues involved in ligand stabilization are conserved across most type-I classical cadherins, suggesting a common general inhibitory mechanism associated with this peptidomimetic compound for this cadherin subset. 
Further hydrophobic contacts are formed by the tertbutyl moiety that was introduced as a protective group at the C-terminus of the ligand and residues such as Thr97 and Pro1o of the protein. However, this moiety of the ligand is rather disordered and therefore other contacts may be dynamically formed with neighboring residues. The isoleucine side chain of the peptide forms hydrophobic contacts with the side chain of Leus and Ile7 in the protein, providing further stabilization energy to the complex. At the other moiety of the ligand, the Aspr side chain of the peptidomimetic forms water-mediated contacts with the carboxy group of Glu13 of the protein. Finally, in the central part of the peptidomimetic ligand, the carbonyl group of the heterocycle forms an hydrogen bonding interaction with the amide of Ser8 of the protein $(2.81 \AA)$. the ligand through its phenyl ring moiety as part of a competitive mechanism with the Trp2 residue of the intact adhesion arm of the protein itself, ${ }^{36}$ the crystal structures shown here provides clear evidence of an inhibitory mechanism whereby the ligand binds across the weakly adhesive X-dimer conformation at the level of the adhesion arms of the two interacting cadherins. This suggests that in intact proteins, which unlike our N-terminally truncated fragment can form strand swap dimers, the binding of FR159 across the intermediate X-dimer provides a physical barrier against the progression of the system towards strand dimer formation and blocks the system at the weakly adhesive X-dimer conformation, as suggested by the binding inhibition data previously reported. In line with these data, we have previously shown $^{36}$ that FR159 can partially inhibit adhesion of E-
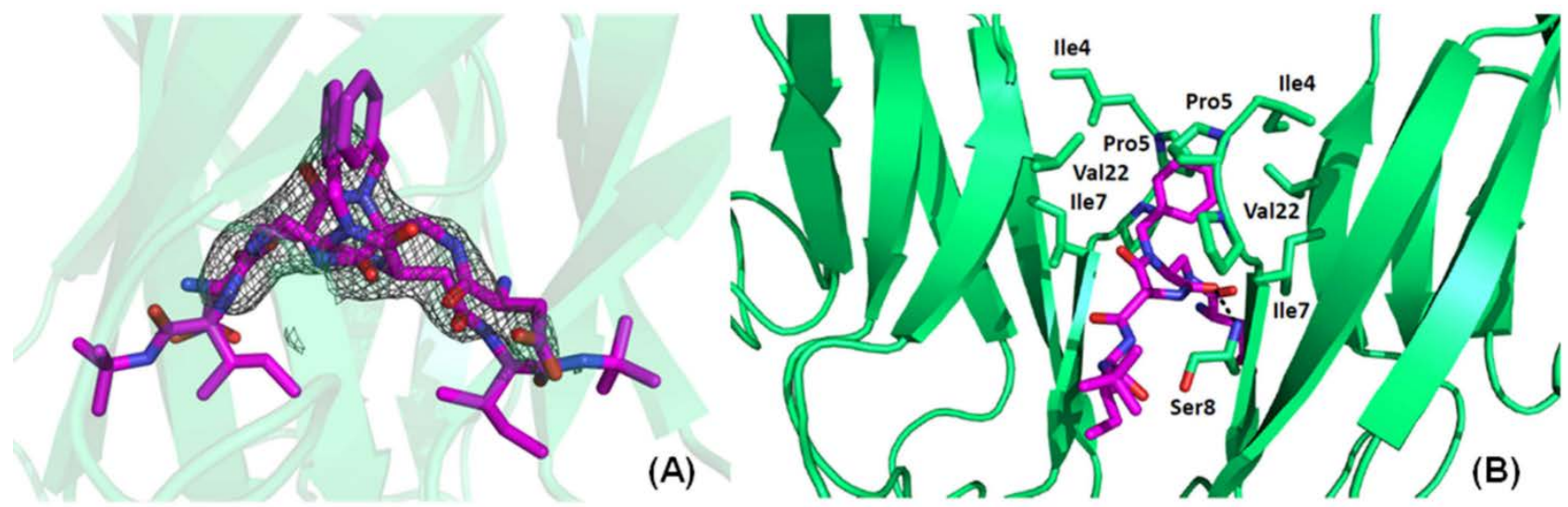

Figure 5 Electron density map of the ligand in the crystal of the complex between human E-cadherin-(Val3)-EC1EC2 and FR159 (PDB id: 4ZTE). The 2Fo-Fc map is shown at the $0.7 \sigma$-level. A double conformation was found for the ligand, the two orientations forming exactly the same set of contacts with each of the two interacting protein fragments owing to the C2 internal symmetry of the complex (A). The stabilizing contacts between the ligand and the protein. For simplicity, only one of the two alternative orientations of the ligand are shown in the picture. Regardless of the orientation, the contacts formed by the ligand with the two interacting proteins are the same. Most contacts are hydrophobic in nature and are within the typical range distance for hydrophobic interactions (4.2-4.5 $\AA$ ) (B).

Each cadherin X-dimer has one inhibitor molecule bound between them. However, in the crystal the peptidomimetic ligand is found in two alternative conformations (each refined with 50\% occupancy in the crystal structure), one rotated relative to the other around the approximate $\mathrm{C}_{2}$ axis of the complex (Fig. 5, A). Interestingly, in the two alternative conformations the two terminal moieties of the ligand are found in the same environment and are stabilized by the same set of contacts with the protein. This is due to the $\mathrm{C}_{2}$ symmetry of the $\mathrm{X}$ dimer configuration and to the constrained "cis" conformation of the ligand.

\section{CONCLUSION}

Here, we provide the first crystal structure of a cadherin fragment in complex with a small molecule inhibitor. This ligand has been previously shown to modulate and partially inhibit cadherin-mediated cell adhesion better than ADH-1, a small cyclic peptide that is currently in phase I clinical trials in cancer patients. Whereas we predict that at some stage in the course of the dimerization process the cadherin binding pocket is also transiently targeted by cadherin-expressing EOC cells, where E-cadherin plays a pro-proliferative role by mediating $\mathrm{PI}_{3} \mathrm{~K} / \mathrm{AKT}$ signaling activation. $^{5}$ Interestingly, in the same E-cadherinexpressing EOC cells, FR159 affects the activation of the $\mathrm{PI}_{3} \mathrm{~K} / \mathrm{AKT}$ signaling pathway (see Supporting Information), indicating that indeed FR159 may help prevent or modulate the growth of EOC cells.

Clearly, the novel structural details shown here allowed for the identification of a druggable pocket formed by two cadherin proteins in the weakly adhesive X-dimer conformation and provide unprecedented opportunities for a structure-based approach to the design and development of inhibitor compounds with enhanced efficacy against cadherin-expressing solid tumors. This could be especially relevant for relapsed EOC patients, in which tumor growth in the peritoneum may be inhibited by targeting up-regulated E-cadherin. Moreover, effective and selective cell-cell junctions modulator peptides may represent potential pharmaceutical excipients to improve drug delivery across biological barriers. ${ }^{37,38}$

\section{EXPERIMENTAL SECTION}


Cloning, expression and purification of human Ecadherin-EC1EC2

A DNA fragment encoding for the $\mathrm{EC}_{1} \mathrm{EC}_{2}$ portion of human E-cadherin and lacking the first two N-terminal residues (Asp1-Trp2) was cloned into a pET-za expression vector (Novagen) using the $\mathrm{NdeI}$ and BlpI restriction sites. This fragment, corresponding to the amino-acid sequence $3-213$ of the protein, was fused at its $\mathrm{N}$ terminus to a 6His-tag, a spacer peptide (Ser-Ser-Gly-His-Ile) and the enterokinase recognition site (Asp-Asp-Asp-Asp-Lys). Overnight protein expression at room temperature in the BL21(DE3)pLysS E.coli strain (Invitrogen) afforded soluble protein in very high yield. Cells were lysed by sonication in TBS, $\mathrm{pH} 7 \cdot 4+1 \mathrm{mM} \mathrm{CaCl}$. The cell lysate was first purified on a Ni-NTA column and then through a Sephacryl 100 HR HiPrep 26/6o size exclusion column (GE Healthcare). Then, the protein was dialyzed in TBS buffer + $20 \mathrm{mM} \mathrm{CaCl}_{2}$, digested with enterokinase (New England Biolabs) at $25^{\circ} \mathrm{C}$, and passed over a Ni-NTA column to remove all traces of the cleaved $6 \mathrm{His}$-tag, as well as any residual un-cleaved protein. The flow-through was then collected and further purified by size exclusion chromatography with TBS $+1 \mathrm{mM} \mathrm{CaCl}$ and finally brought to a concentration of $12 \mathrm{mg} / \mathrm{ml}$ for crystallization experiments.

\section{Peptidomimetic design and synthesis}

The synthesis and characterization of FR159 has been described previously. ${ }^{36}$ Copies of the ${ }^{1} \mathrm{H}$ and ${ }^{13} \mathrm{C}$ NMR spectra and the HPLC-MS chromatogram are reported in the Supporting Information. HPLC-MS data were collected with an Agilent 1100 HPLC connected to a Bruker Esquire 300o+ ion trap mass spectrometer through an ES interface. FR 159 was found to be $\geq 95 \%$ pure by LC-MS.

\section{Co-crystallization and data collection}

Crystals of the protein alone and the protein-ligand complex were obtained by the vapor diffusion method at room temperature from a $1.3 \mathrm{M}$ ammonium sulfate, 80 $\mathrm{mMCaCl}_{2}$, o.1 M Tris $\mathrm{pH} 8.5$ crystallization solution. Crystals were then frozen in $25 \%(\mathrm{v} / \mathrm{v})$ glycerol for X-ray diffraction data collection. A $1.9 \AA$ resolution data set and a 2.13 $\AA$ data set were collected from a E-cadherin-(Val3)$E_{1} E C_{2}$ crystal of $0.20 \times 0.15 \times 0.15 \mathrm{~mm}$ size and from a $0.15 \times 0.15 \times 0.10 \mathrm{~mm}$ crystal of E-cadherin-(Val3)-EC1EC2 in complex with FR159, respectively. In both cases, a $\lambda=$ $1.000 \AA$ radiation in the Xo6DA-PXIII beamline at the Swiss Light Source (Paul Scherrer Institute, Villigen, Switzerland) was used. Diffraction images were processed and scaled using XDS. ${ }^{39}$ Data collection and refinement statistics are shown in Table 1.

\section{Structure determination}

The structure was determined by molecular replacement using Molrep ${ }^{40}$ from the $\mathrm{CCP}_{4}$ package $^{41}$ and the human E-cadherin-EC1EC2 crystal structure (PDB id: ${ }_{2} \mathrm{O}_{72}$ ) as the search probe. Model refinement was carried out using Refmac5 and Phenix. ${ }^{42,43}$ Water molecules were added both automatically using the program Phenix refine $^{43}$ and manually from visual inspection of the electron density map. Figures 3, 4 and 5 in the paper were generated using PyMOL ("www.pymol.org,"). The refinement converged to a final $\mathrm{R} / \mathrm{R}_{\text {free }}=19.4 / \mathbf{2 2 . 1} \%$ for the un-ligated structure and $R / R_{\text {free }}=18.5 / 23.0 \%$ for the complex .

\section{CRYSTALLOGRAPHIC TABLE}

\begin{tabular}{|c|c|c|}
\hline & $\begin{array}{c}\text { E-cadherin- } \\
\text { EC1EC2 }\end{array}$ & $\begin{array}{c}\text { E-cadherin- } \\
\text { EC1EC2 / FR159 }\end{array}$ \\
\hline Space group & $C_{121}$ & C 121 \\
\hline Cell dimensions & & \\
\hline$a(\AA)$ & 120.45 & 120.58 \\
\hline$b(\AA)$ & 76.42 & 76.83 \\
\hline$c(\AA)$ & 73.02 & 72.77 \\
\hline Wavelength (Å) & 1.000 & 1.000 \\
\hline Resolution (Å) & $42.66-1.92$ & $42.26-2.13$ \\
\hline $\boldsymbol{R}_{\text {sym }}$ or $\boldsymbol{R}_{\text {merge }}(\%)$ & $4.5(17.6)$ & $12.9(12.3)$ \\
\hline$I / \sigma I$ & $8.4(2.9)$ & $7 \cdot 3(0.6)$ \\
\hline Completeness (\%) & $98.1(96.2)$ & $98.7(93.5)$ \\
\hline Multiplicity & 2.0 & 6.0 \\
\hline No. of reflections & 45679 & 33775 \\
\hline $\boldsymbol{R}_{\text {work }} / \boldsymbol{R}_{\text {free }}(\%)$ & $19.4 / 22.1$ & $18.5 / 23.0$ \\
\hline No. of atoms & & \\
\hline Protein & 3180 & 3196 \\
\hline Ligand $\left(\mathrm{Ca}^{2+} / \mathrm{FR} 159\right)$ & 6 & $6 / 82$ \\
\hline Water & 382 & 229 \\
\hline Average B-factors $\left(\AA^{2}\right)$ & & \\
\hline Protein & 46.20 & 46.86 \\
\hline Ligand: $\mathrm{Ca}^{2+} / \mathrm{FR}_{159}$ & 30.87 & $32.18 / 73.68$ \\
\hline Water & 47.68 & $47 \cdot 54$ \\
\hline r.m.s.d. & & \\
\hline Bond lengths $(\AA ̊)$ & 0.003 & 0.003 \\
\hline Bond angles $\left(^{\circ}\right)$ & 0.513 & 0.487 \\
\hline Ramachandran & & \\
\hline Most favored (\%) & 97 & 97 \\
\hline Allowed (\%) & 3 & 3 \\
\hline Disallowed (\%) & o & o \\
\hline
\end{tabular}

Table 1. Crystallographic data of the free and the ligandbound crystal structures of E-cadherin-EC1EC2 (PDB id: 4ZT1 and 4ZTE, respectively).

\section{ASSOCIATED CONTENT}

\section{Supporting information}

The Supporting Information is available free of charge on the ACS Publications website: Best Calculated poses for FR 159 in complex with E- and N-cadherin, characterization of compound FR159, inhibition of phosphorylated AKT by FR159.

\section{AUTHOR INFORMATION}

Corresponding author

*Phone: +39-02-23999870. E-mail: Emilio.Parisini@iit.it

\section{Author Contributions}

\pm These authors contributed equally to this work.

Notes

The authors declare no competing financial interests. 


\section{ACKNOWLEDGMENTS}

We thank the Xo6DA-PXIII beamline personnel of the Paul Scherrer Institute, Villigen $(\mathrm{CH})$. E.P. thanks the Istituto Italiano di Tecnologia and the European Union ("Marie Curie" FP7-PEOPLE-2010-IRG grant N. 268231-DETACH) for funding. Ministero dell'Università e della Ricerca and AIRC are gratefully acknowledged for financial support to M.C. (RBFRo88ITV project) and A.T.(IG13055 grant), respectively.

\section{ABBREVIATION USED}

Surface Plasmon Resonance (SPR); epithelial-tomesenchymal transition (EMT); Epithelial ovarian cancer (EOC); extracellular cadherin domain (EC).

\section{ACCESSION CODES}

Final crystallographic coordinates are available in the RCSB PDB (4ZT1 and 4ZTE).

\section{REFERENCES}

1) Gumbiner, B. M. Regulation of cadherin-mediated adhesion in morphogenesis. Nature Reviews. Mol. Cell. Biol., 2005, 6, 622-634.

2) Leckband, D.; Sivasankar, S. Cadherin recognition and adhesion. Curr. Opin. Cell Biol., 2012, 24, 620-627.

3) Blaschuk, O. W.; Devemy, E. Cadherins as novel targets for anti-cancer therapy. Eur. J. Pharmacol., 2009, 625, 195-198.

4) Berx, G.; Van Roy, F. Involvement of members of the cadherin superfamily in cancer. Cold Spring Harb. Perspect. Biol., 2009, 1, ao03129.

5) De Santis, G.; Miotti, S.; Mazzi, M.; Canevari, S.; Tomassetti, A. E-cadherin directly contributes to $\mathrm{PI}_{3} \mathrm{~K} / \mathrm{AKT}$ activation by engaging the $\mathrm{PI}_{3} \mathrm{~K}-\mathrm{p} 85$ regulatory subunit to adherens junctions of ovarian carcinoma cells. Oncogene, 2009, 28, 1206-1217.

6) Paredes, J.; Figueiredo, J.; Albergaria, A.; Oliveira, P.; Carvalho, J.; Ribeiro, A. S.; Caldeira, J.; Costa, A. M.; Simões-Correia, J.; Oliveira, M. J.; Pinheiro, H.; Pinho, S. S.; Mateus, R.; Reis, C. A.; Leite, M.; Fernandes, M. S.; Schmitt, F.; Carneiro, F.; Figueiredo, C.; Oliveira, C.; Seruca, R. Epithelial E- and P-cadherins: Role and clinical significance in cancer. Biochim. Biophys. Acta, 2012, 1826, 297-311.

7) Imai, K.; Hirata, S.; Irie, A.; Senju, S.; Ikuta, Y.; Yokomine, K.; Harao, M.; Inoue, M.; Tsunoda, T.; Nakatsuru, S.; Nakagawa, H.; Nakamura, Y.; Baba, H.; Nishimura, Y. Identification of a novel tumor-associated antigen, cadherin $3 / \mathrm{P}$-cadherin, as a possible target for immunotherapy of pancreatic, gastric, and colorectal cancers. Clin. Cancer Res., 2008, 14, 6487-6495.

8) Park, J.; Park, E.; Han, S.-W.; Im, S.-A.; Kim, T.-Y.; Kim, W.-H.; Oh, D. Y.; Bang, Y.-J. Down-regulation of Pcadherin with PF-03732010 inhibits cell migration and tumor growth in gastric cancer. Invest. New Drug., 2012, 30, 1404-1412.

9) Sarrió, D.; Rodriguez-Pinilla, S. M.; Cano, A.; MorenoBueno, G.; Palacios, J. Epithelial-mesenchymal transition in breast cancer relates to the basal-like phenotype. Cancer Res.,20o8,68, 989-997.

10) Hazan, R. B.; Qiao, R.; Keren, R.; Badano, I.; Suyama, K. Cadherin switch in tumor progression. Ann. N. Y. Acad. Sci.,2004, 1014, 155-163.

11) Lee, D. M.; Kiener, H. P.; Agarwal, S. K.; Noss, E. H.; Watts, G. F.; Chisaka, O.; Takeichi, M.; Brenner, M. B.
Cadherin-11 in synovial lining formation and pathology in arthritis. Science, 2007, 315, 1006-1010.

12) Assefnia, S.; Dakshanamurthy, S.; Guidry Auvil, J. M.; Hampel, C.; Anastasiadis, P. Z.; Kallakury, B.; Uren, A.; Foley, D. W.; Brown, M. L.; Shapiro, L.; Brenner, M.; Haigh, D.; Byers, S. W. Cadherin-11 in poor prognosis malignancies and rheumatoid arthritis: common target, common therapies. Oncotarget,2014, 5, 1458-1474.

13) Shapiro, L.; Fannon, A. M.; Kwong, P. D.; Thompson, A.; Lehmann, M. S.; Grübel, G.; Legrand, J. F.; Als-Nielsen, J.; Colman, D. R.; Hendrickson, W. A. Structural basis of cell-cell adhesion by cadherins. Nature, 1995, 374, 327337.

14） Nagar, B.; Overduin, M.; Ikura, M.; Rini, J. Structural basis of calcium-induced E-cadherin rigidification and dimerization. Nature, 1996, 380, 360-364.

15) Pertz, O.; Bozic, D.; Koch, A. W.; Fauser, C.; Brancaccio, A.; Engel, J. A new crystal structure , Ca 2+ dependence and mutational analysis reveal molecular details of Ecadherin homoassociation. EMBO J., 1999, 18, 1738-1747.

16) Boggon, T. J.; Murray, J.; Chappuis-Flament, S.; Wong, E.; Gumbiner, B. M.; Shapiro, L. C-cadherin ectodomain structure and implications for cell adhesion mechanisms. Science, 2002, 296, 1308-1313.

17) Parisini, E.; Higgins, J. M. G.; Liu, J.; Brenner, M. B.; Wang, J. The crystal structure of human E-cadherin domains 1 and 2, and comparison with other cadherins in the context of adhesion mechanism. J. Mol. Biol., 2007, 373, 401-411.

18) Vendome, J.; Posy, S.; Jin, X.; Bahna, F.; Ahlsen, G.; Shapiro, L.; Honig, B. Molecular design principles underlying $\beta$-strand swapping in the adhesive dimerization of cadherins. Nat. Struct. Mol. Biol., 2011, 18, 693700.

19) Dalle Vedove, A.; Lucarelli, A. P.; Nardone, V.; Matino, A.; Parisini, E. The X-ray structure of human P-cadherin $\mathrm{EC}_{1}-\mathrm{EC}_{2}$ in a closed conformation provides insight into the type I cadherin dimerization pathway. Acta Crystallogr. F Struct. Biol. Commun., 2015, F71, 371-38o.

20) Patel, S. D.; Ciatto, C.; Chen, C. P.; Bahna, F.; Rajebhosale, M.; Arkus, N.; Schieren, I.; Jessell, T. M.; Honig, B.; Price, S. R.; Shapiro, L. Type II cadherin ectodomain structures: implications for classical cadherin specificity. Cell, 2006, 124, 1255-1268.

21) Miloushev, V. Z.; Bahna, F.; Ciatto, C.; Ahlsen, G.; Honig, B.; Shapiro, L.; Palmer, A. G. 3d. Dynamic Properties of a Type II Cadherin Adhesive Domain: Implications for the Mechanism of Strand-Swapping of Classical Cadherins. Structure, 2008, 16, 1195-1205.

22) Harrison, O. J.; Bahna, F.; Katsamba, P. S.; Jin, X.; Brasch, J.; Vendome, J.; Ahlsen, G.; Carroll, K. J.; Price, S. R.; Honig, B.; Shapiro, L. Two-step adhesive binding by classical cadherins. Nat. Struct. Mol. Biol., 2010, 17, 348-357.

23) Ciatto, C.; Bahna, F.; Zampieri, N.; Van Steenhouse, H. C.; Katsamba, P. S.; Ahlsen, G.; Harrison, O. J.; Brasch, J.; Jin, X.; Posy, S.; Vendome, J.; Ranscht, B.; Jessell, T. M.; Honig, B.; Shapiro, L. T-cadherin structures reveal a novel adhesive binding mechanism. Nat. Struct. Mol. Biol., 2010, 17, 339-347.

24) Kudo, S.; Caaveiro, J. M. M.; Goda, S.; Nagatoishi, S.; Ishii, K.; Matsuura, T.; Sudou, Y.; Kodama, T.; Hamakubo, T.; Tsumoto, K. Identification and characterization of the X-dimer of human P-cadherin: implications for homophilic cell adhesion. Biochemistry, 2014, 53, 17421752. 
25) Rakshit, S.; Zhang, Y.; Manibog, K.; Shafraz, O.; Sivasankar, S. Ideal, catch, and slip bonds in cadherin adhesion. Proc. Natl. Acad. Sci. USA, 2012, 109, 1881518820.

26) Li, Y.; Altorelli, N. L.; Bahna, F.; Honig, B.; Shapiro, L.; Palmer, A. G. 3d. Cadherin recognition and adhesion. Proc. Natl. Acad. Sci. USA, 2013, 110, 16462-16467.

27) Häussinger, D.; Ahrens, T.; Aberle, T.; Engel, J.; Stetefeld, J.; Grzesiek, S. Proteolytic E-cadherin activation followed by solution NMR and X-ray crystallography. EMBO J., 2004, 23, 1699-1708.

28) Williams, E.; Williams, G.; Gour, B. J.; Blaschuk, O. W.; Doherty, P. A novel family of cyclic peptide antagonists suggests that $\mathrm{N}$-cadherin specificity is determined by amino acids that flank the HAV motif. J. Biol. Chem., 2000, 275, 4007-4012.

29) Williams, G.; Williams, E. J.; Doherty, P. Dimeric versions of two short $\mathrm{N}$-cadherin binding motifs (HAVDI and INPISG) function as N-cadherin agonists. J. Biol. Chem., 2002, 277, 4361-4367.

30) Burden-Gulley, S. M.; Gates, T. J.; Craig, S. E.; Lou, S. F.; Oblander, S. A.; Howell, S.; Gupta, M.; Brady-Kalnay, S. M. Novel peptide mimetic small molecules of the HAV motif in N-cadherin inhibit $\mathrm{N}$-cadherin-mediated neurite outgrowth and cell adhesion. Peptides, 20o9, 30, 2380-2387.

31) Blaschuk, O. W. Discovery and development of Ncadherin antagonists. Cell Tissue Res., 2012, 348, 309313.

32) Perotti, A.; Sessa, C.; Mancuso, A.; Noberasco, C.; Cresta, S.; Locatelli, A.; Carcangiu, M. L.; Passera, K.; Braghetti, A.; Scaramuzza, D.; Zanaboni, F.; Fasolo, A.; Capri, G.; Miani, M.; Peters, W. P.; Gianni, L. Clinical and pharmacological phase I evaluation of Exherin (ADH-1), a selective anti-N-cadherin peptide in patients with $\mathrm{N}$ cadherin-expressing solid tumours. Ann. Oncol., 2009, 20, 741-745.

33) Yarom, N.; Stewart, D.; Malik, R.; Wells, J.; Avruch, L.; Jonker, D. J. Phase I clinical trial of Exherin (ADH-1) in patients with advanced solid tumors. Curr. Clin. Pharmacol., 2013, 8, 81-88.

34) Blundell, T. L.; Burke, D. F.; Chirgadze, D.; Dhanaraj, V.; Hyvönen, M.; Innis, C. A.; Parisini, E.; Pellegrini, L.; Sayed, M.; Sibanda, B. L. Protein-protein interactions in receptor activation and intracellular signalling. Biol. Chem., 2000, 381, 955-959.
35) Jubb, H.; Blundell, T. L.; Ascher, D. B. Flexibility and small pockets at protein-protein interfaces: New insights into druggability. Prog. Biophys. Mol. Biol., 2015, 119, 2-9.

36) Doro, F.; Colombo, C.; Alberti, C.; Arosio, D.; Belvisi, L.; Casagrande, C.; Fanelli, R.; Manzoni, L.; Parisini, E.; Piarulli, U.; Luison, E.; Figini, M.; Tomassetti, A.; Civera, M. Computational design of novel peptidomimetic inhibitors of cadherin homophilic interactions. Org. Biomol. Chem., 2015, 13, 2570-2573.

37) Bocsik, A.; Walter, F.R.; Gyebrovszki, A.; Fülop, L.; Blasig, I.; Dabrowski, S.; Ötvös, F.; Tóth, A.; Rákhely, G.; Veszelka, S.; Vastag, M.; Szabó-Révész, P.; Deli M.A. Reversible opening of intercellular junctions of intestinal epithelial and brain endothelial cells with tight junction modulator peptides. J. Pharm. Sci., 2016, 105, 754-765.

38) Alaofi, A.; On, N; Kiptoo, P.; Williams, T.D. Miller, D.W.; Siahaan, T.J. Comparison of linear and cyclic HisAla-Val peptides in modulating the blood-brain barrier permeability: impact on delivery of molecules to the brain. J. Pharm. Sci., 2016, 105, 797-807.

39) Kabsch, W. XDS. Acta Crystallog. D, Biol. Crystallogr., 2010, 66, 125-132.

40) Vagin, A.; Teplyakov, A. MOLREP : an Automated Program for Molecular Replacement. J. Appl. Crystallogr., *1997, 30, 1022.

41) Winn, M. D.; Ballard, C. C.; Cowtan, K. D.; Dodson, E. J.; Emsley, P.; Evans, P. R.; Keegan, R. M.; Krissinel, E. B.; Leslie, A. G.; McCoy, A.; McNicholas, S. J.; Murshudov, G. N.; Pannu, N. S.; Potterton, E. A.; Powell, H. R.; Read, R. J.; Vagin, A.; Wilson K.S. Overview of the $\mathrm{CCP}_{4}$ suite and current developments. Acta Crystallogr. D, Biol. Crystallogr., 2011, D67, 235242.

42) Murshudov, G. N.; Vagin, A. A.; Dodson, E. J. Refinement of macromolecular structures by the maximumlikelihood method. Acta Crystallogr. D, Biol. Crystallogr., 1997, 53, 240-255.

43) Adams, P. D.; Afonine, P. V.; Bunkóczi, G.; Chen, V. B.; Davis, I. W.; Echols, N.; Headd, J. J.; Hung, L. W.; Kapral, G. J.; Grosse-Kunstleve, R. W.; McCoy, A. J.; Moriarty, N. W.; Oeffner, R.; Read, R. J.; Richardson, D. C.; Richardson, J. S.; Terwilliger, T. C.; Zwart, P. H. PHENIX: a comprehensive Python-based system for macromolecular structure solution. Acta Crystallogr. D, Biol. Crystallogr., 2010, 66, 213-221.

\section{Insert Table of Contents artwork here}

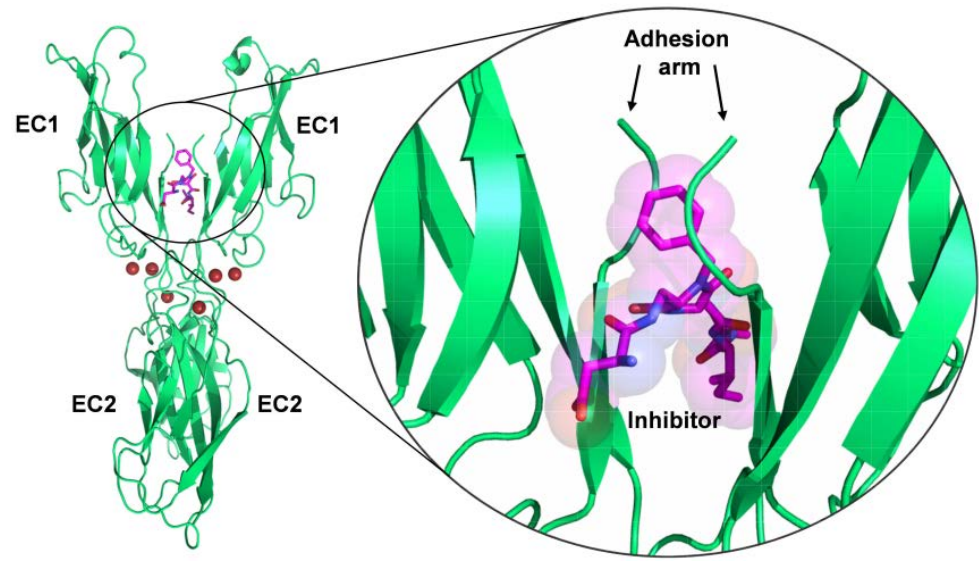

